\title{
Biogerontology: The Next Step
}

\author{
SURESH I.S. RATTAN ${ }^{a}$ \\ Laboratory of Cellular Ageing, Danish Centre for Molecular Gerontology, Department of \\ Molecular and Structural Biology, University of Aarhus, Gustav Wieds Vej, DK-8000 \\ Aarhus - C, Denmark
}

\begin{abstract}
After a long period of collecting empirical data describing the changes in organisms, organs, tissues, cells, and macromolecules, biogerontological research is now able to develop various possibilities for intervention. Because aging is a stochastic and nondeterministic process characterized by a progressive failure of maintenance and repair, it is reasoned that genes involved in homeodynamic repair pathways are the most likely candidate gerontogenes. A promising approach for the identification of critical gerontogenic processes is through the hormesis-like positive effects of mild stress. Stimulation of various repair pathways by mild stress has significant effects on delaying the onset of various age-associated alterations in cells, tissues, and organisms.
\end{abstract}

The study of the biological basis of aging, biogerontology, is now ready to take the next step. After decades of systematic collection of data describing the changes in organisms, organs, tissues, cells and macromolecules, it is clear that although the basic biochemistry of all living systems is very much alike, there are no universal patterns of aging and age-related alterations (TABLE 1). Collecting more descriptive data by using more powerful techniques will only strengthen this fact. Most importantly, like any other mature field of intellectual enquiry, biogerontology is now able to accept such differences in the progression of aging, which is indicative of the fact that biogerontology is now a mature science. Hence, the practitioners of biogerontology (biogerontologists) do not need to anymore hide their identities behind any other "-logy"!

\section{ESSENTIAL LIFESPAN AND AGING}

Aging is a nondeterministic stochastic phenomenon occurring mainly as a result of the failure of homeodynamics and an organism's inability to prevent it. ${ }^{1-3}$ The evolutionary theories strongly argue against the existence of genes that may have evolved specifically to cause aging and to determine maximum lifespan of an organism. The genetic regulation of lifespan is primarily in terms of determining what can be called as the essential lifespan (ELS) of a species, which is the time required to fulfill the Darwinian purpose of life, that is, successful reproduction and continua-

\footnotetext{
${ }^{a}$ Address for correspondence: Phone: +45 8942 5034; fax: +45 86123178.

rattan@imsb.au.dk
} 
TABLE 1. General observations on the aging phenotype
The phenotype and rate of progression of aging are:
- different in different species;
- different in different individuals;
- different in different organs, systems, and tissues;
- different in different cells;
- different in different organelles; and
- different in different macromolecules.

tion of generations. For example, species undergoing fast maturation and early onset of reproduction with large reproductive potential generally have a short ELS. ${ }^{4-6}$ In contrast, slow maturation, late onset of reproduction, and small reproductive potential of a species is concurrent with its long ELS. ${ }^{4-6}$ Therefore, from an evolutionary point of view, the term "maximum lifespan" is meaningless because of the fact that the extended survival of a small number of individuals to very late ages, as compared with the majority of the population in the wild, has no significance in the context of the declining force of natural selection with age.

The genes that do influence longevity are those that have evolved in accordance with the life history of a species for assuring the ELS. Such genes are termed longevity assurance genes ${ }^{7}$ or vitagenes ${ }^{8}$ and are considered to constitute various maintenance and repair pathways, including antioxidative defenses, DNA repair, fidelity of genetic information transfer, and stress response pathways. There are several examples of genes, particularly in DNA repair and antioxidant pathways, whose activities have been reported to correlate directly with species lifespan. ${ }^{9-11}$ Further evidence that the maintenance and repair pathways are the main determinants of longevity comes from experiments performed to retard aging and to increase the lifespan of organisms. ${ }^{11,12}$

It is the longevity-assuring vitagenes in the maintenance and repair pathways that set limits to the ELS of a species and that are integral to an evolutionarily determined developmental period. Aging, however, is the postdevelopmental and often postreproductive period, observed most commonly in protected environments that permit the survival of an individual much beyond its ELS. A progressive impairment of functional ability and increased chances of death generally characterize this extended period of life. Furthermore, the diversity of the forms and variations in which agerelated alterations are manifested underline the fact that the progression of aging is not programmed or deterministic but is stochastic in nature (TABLE 1). A large body of descriptive data clearly shows that individually no tissue, organ, or system becomes functionally exhausted, even in very old organisms. Instead, it is their combined interaction and interdependence that determines the survival of the whole. It has been suggested that age-related alterations observed at all levels of organization are the sign of continuous remodeling of the body, ${ }^{13}$ which is a kind of a survival instinct response for counteracting the ill effects of progressively failing repair and maintenance processes. 


\section{GERONTOGENES}

In an evolutionary sense, it is meaningless to use the term gerontogenes. For practical purposes, however, it may be appropriate to invoke this term in order to focus any discussion about the gene-based biochemical processes involved in aging and to describe genes whose altered activity influences aging and longevity. ${ }^{12,14}$ Two kinds of gerontogene action are postulated to be responsible for the emergence of the aging phenotype. The first considers the role of late-acting mutations that are already present at the time of fertilization and birth and show their deleterious effects after the period of growth, development, and maturation. The second category of gene action is referred to as the antagonistic pleiotropy, which involves genes selected for beneficial effects during early development, but have harmful effects in postreproductive life when they escape the force of natural selection. ${ }^{15-17}$ In both cases, these genes were not selected as the real genes to cause aging, but manifest themselves only as virtual gerontogenes because of their involvement in the progression of aging. 8,12

Until now, several putative gerontogenes have been reported for various aging systems, including yeast, nematodes, insects, and mammals. The molecular identities of some of these genes have been established. In the case of the budding yeast, the nematode, and the fruitfly, these genes are longevity-determining genes, but the molecular pathways affected by them have little or no similarity among different organisms. For example, in S. cerevisiae, the functions of the LAG, RAS, uth, and Sir complex range from being transmembrane proteins to transcriptional silencing of telomeres. ${ }^{7,15,18-22}$ In C. elgans, the normal functions of various gerontogenes include PI3-kinase activity, tyrosine kinase receptor activity, transcription factor activity, and insulin receptor-like activity, and it is only when mutated that a loss or alteration in the activity of their gene products is associated with increased longevity. ${ }^{23-26}$ There are several other candidate gerontogenes, such as four clock genes clk-1, clk2, clk-3, and gro-127, and age-228 in C. elegans, discovered for their effects on longevity, but whose molecular identities are yet to be established. In Drosophila, the methuselah ( $m$ th $)$ gene, whose predicted protein sequence has homology to several GTP-binding protein-coupled receptors, is also associated with increased lifespan and enhanced resistance to various forms of stress. ${ }^{29}$ However, in the case of the mouse klotho gene, which is a membrane protein $\beta$-glucosidase, ${ }^{30}$ and the human Werner's gene, which is a DNA helicase, ${ }^{31}$ the phenotype of premature aging is manifested along with a plethora of diseases.

Additionally, genetic linkage studies for longevity in mice have identified major histocompatibility complex (MHC) regions, ${ }^{32}$ and quantitative trait loci (QTL) on chromosomes $7,10,11,12,16,18$, and $19^{33,34}$ as putative gerontogenes. In human centenarians, certain alleles of the HLA locus on chromosome 6, different alleles of ApoE and ApoB, and the DD genotype of angiotensin-converting enzyme (ACE) have been linked to their long lifespan. ${ }^{32,35,36}$ The diversity of the genes associated with aging and longevity of different organisms indicates that whereas the genes involved in repair and maintenance pathways may be important from an evolutionary point of view (the so-called "public" genes), each species may also have additional "private" 37 gerontogenic pathways that influence its aging phenotype. 
TABLE 2. Major age-related alterations during cellular aging in vitro

Structural changes
Increase in cell size; change of shape from thin, long, and spindle-like to flattened and
irregular; loss of fingerprint-like arrangement in parallel arrays; increased number of
vacuoles and dense lysosomal residual bodies containing UV-fluorescent pigments;
rodlike polymerization of the cytoskeletal actin filaments and disorganized microtu-
bules; and increased level of chromosomal aberrations and multinucleation.
Physiological changes
Reduced response to growth factors and other mitogens; increased sensitivity to toxins,
drugs, irradiation, and other stress; altered calcium flux, pH, viscosity, and membrane
potential; reduced respiration and energy metabolism; and increased duration of G1
phase of the cell cycle.
Biochemical and molecular changes
Decreased activity, specificity, and fidelity of various enzymes; accumulation of post-
translationally modified and inactivated proteins; reduced rates of protein synthesis
and degradation; increased levels of oxidative damage in nuclear and mitochondrial
DNA; reduced levels of methylated cytosines; reduced length of telomeres; and
altered (increased or decreased) expression of several genes.

\section{CELLULAR AGING IN VITRO}

An experimental system that has been used extensively for the identification of genes involved in aging is the so-called Hayflick system of cellular aging in vitro. It is now well established that normal diploid cells of various kinds and from various species have a limited proliferative potential in vitro. The ultimate phenotype of the serially passaged diploid cell is the permanent arrest of late-passage or high population doubling level (PDL) cells in late- $\mathrm{G}_{1} / \mathrm{S}$ phase boundary of the cell cycle. Most of the studies on the identification of gerontogenes in this model system have focussed on this endpoint phenotype, also known as replicative senescence. Several genes have been identified whose products either act as active regulators of cell cycle-arrest or correlate with replicative senescence. ${ }^{38-44}$ These genes are generally involved in either the activation or the inhibition of the protein phosphorylation and dephosphorylation cascade involving various transcription factors and cyclin complexes in association with the p53 and Rb genes. ${ }^{45-49}$ Experimentally induced or spontaneous immortalization of such cells in vitro and cancer cells in vivo is almost always accompanied by the deregulation of these genes.

It is important to realize that the irreversible cell cycle-arrest is the ultimate phenotype reached after a long period of active cell proliferation. Furthermore, the replicative senescent phenotype may never be achieved in vivo for many cell types, such as fibroblasts, epithelial cells, endothelial cells and osteoblasts. Numerous studies have been performed that show that cellular aging in vitro is accompanied by a whole range of physiological, metabolic, biochemical, and molecular changes that occur progressively throughout the replicative lifespan of cells in vitro, culminating in the cessation of cell proliferation. Some of the major characteristics of cellular aging are summarized in TABLE 2. 
Progressive accumulation of stochastically occurring damage is the hallmark of cellular aging in vitro and is the signal for the activation and upregulation of various genes whose products then act towards arresting and maintaining the senescent cell in a permanent state of growth arrest. ${ }^{50-52}$ Experimental induction of damage by free radicals and excessive loss of telomeres by severe growth arrest results in the premature onset of the senescent phenotype (both in normal and transformed cells) by the resultant rapid activation of the so-called senescence-specific genes. ${ }^{53,54}$ Thus the significance of the cellular aging system in vitro can be best realized as a model to study progressive accumulation of damage in cells resulting in their physiological impairment.

\section{CELLULAR RESPONSIVENESS AND HORMESIS}

Using the model system of cellular aging, it has been shown that, whereas the cellular response to various growth factors and mitogens is significantly reduced during aging, their sensitivity to toxins, antibiotics, irradiation, oxidants, and heat shock is increased. ${ }^{55,56}$ Furthermore, induction of high levels of stress, particularly oxidative stress, has been used as a tool to induce replicative senescence or irreversible growth arrest by increasing the intracellular damage resulting in the upregulation of the socalled senescence-specific genes described above. ${ }^{52}$ Although such an experimental approach can facilitate the understanding of the regulation and interactions of various cell cycle-checkpoint genes, this approach has only a limited value in identifying genes involved in maintaining various pathways of maintenance and repair. Therefore, other experimental strategies are required for identifying gerontogenes that influence the basic process of aging.

It has been suggested that if cells and organisms are exposed to brief periods of stress so that their stress response-induced gene expression is upregulated and the related pathways of maintenance and repair are stimulated, one should observe antiaging and longevity-promoting effects. Such a phenomenon, in which stimulatory responses to low doses of otherwise harmful conditions improve health and enhance lifespan, is known as hormesis. ${ }^{57-60}$

Anti-aging and life-prolonging hormesis-like effects of thermal stress have been reported for Drosophila, ${ }^{61}$ nematodes, ${ }^{62,63}$ and yeast. ${ }^{64}$ In Drosophila, the mild stress of hypergravity exposure has been shown to delay aging, to increase longevity, and to increase resistance to heat shock. ${ }^{65}$ Similarly, low doses of ionizing radiation have been shown to increase the lifespan of mice ${ }^{66}$ and may have several beneficial effects on human health, especially in terms of prevention and treatment of neurodegenerative diseases and cancers. ${ }^{67-69}$ The beneficial effects of exercise, which stimulates the production of reactive oxygen species, ${ }^{70,71}$ and the life-extending effects of calorie restriction have been suggested to work through hormesis. ${ }^{72}$ In the case of cellular aging in vitro, repeated low doses of $\gamma$ - and X-rays have been shown to prolong the cellular lifespan. ${ }^{73-75}$ Anti-aging effects of repeated mild heat shock on human skin fibroblasts have also been reported. ${ }^{76}$

Therefore, it may be possible to use the approach of hormesis in order to identify genes that are important for aging and longevity. For example, if repeated mild heatshock treatment has life-prolonging and anti-aging effects in cells and organisms, it is likely that the genetic pathways of the heat-shock response are also associated 
with longevity determination. Similarly, other chemical, physical, and biological treatments can be used to unravel various pathways of maintenance and repair whose sustained activities improve the physiological performance and survival of cells and organisms. This will be helpful not only for having a complete understanding of the mechanistic aspects of the aging process, but also for preventing the onset of various age-related diseases by maintaining the efficiency of repair processes.

Some of the main targets for prevention of age-related pathology include the following biochemical processes which may be accessible to modulation through hormesis: (1) the appearance and accumulation of abnormal proteins and proteolytic products leading to, for example, Alzheimer's disease; (2) posttranslational modifications and crosslinks between macromolecules, leading to, for example, cataracts and atherosclerosis; (3) reactive oxygen species-induced mitochondrial defects leading to, for example, Parkinson's disease, Huntington's disease, and amyotropic lateral sclerosis; and (4) genomic instability leading to, for example, cancers.

The clinical implications of the hormesis-like stress response in the diagnosis and treatment of several diseases including arthritis, Duchenne muscular dystrophy, multiple sclerosis, myocardial ischemia, mitochondrial encephalomyopathy, some cancers, and autoimmune diseases such as systemic lupus erythematosis are being increasingly realized. ${ }^{77}$ In the case of aging research, although at present there are only a few studies performed that utilize mild stress as a modulator of aging and longevity, hormesis appears to be the next step and represents a promising experimental approach in biogerontology.

\section{ACKNOWLEDGMENT}

This project is a part of the shared cost action program GENAGE under the EU Biomed and Health Programme Projects.

\section{REFERENCES}

1. Rose, M.R. 1991. Evolutionary Biology of Aging. Oxford University Press. New York.

2. KirKWOOD, T.B.L. 1977. Evolution of ageing. Nature 270: 301-304.

3. Partridge, L. \& N.H. Barton. 1993. Optimality, mutation and the evolution of ageing. Nature 362: 305-311.

4. Finch, C.E. 1990. Longevity, Senescence, and the Genome. The University of Chicago Press. Chicago.

5. FINCH, C.E. 1998. Variations in senescence and longevity include the possibility of negligible senescence. J. Gerontol. Biol. Sci. 53A: B235-B239.

6. Holliday, R. 1994. Longevity and fecundity in eutherian mammals. In Genetics and Evolution of Aging. M.R. Rose \& C.E. Finch, Eds. Kluwer Academic Publishers. Amsterdam, The Netherlands.

7. D'mello, N.P., A.M. Childress, D.S. Franklin, et al. 1994. Cloning and characterization of $L A G 1$, a longevity-assurance gene in yeast. J. Biol. Chem. 269: 15451-15459.

8. RatTAn, S.I.S. 1998. The nature of gerontogenes and vitagenes. Antiaging effects of repeated heat shock on human fibroblasts. Ann. N.Y. Acad. Sci. 854: 54-60.

9. Holliday, R. 1995. Understanding Ageing. Cambridge University Press. Cambridge, U.K.

10. RATTAN, S.I.S. 1989. DNA damage and repair during cellular aging. Int. Rev. Cytol. 116: $47-88$.

11. RatTAn, S.I.S. 1995. Ageing - a biological perspective. Mol. Aspects Med. 16: 43-508. 
12. RATTAN, S.I.S. 1995. Gerontogenes: real or virtual? FASEB J. 9: 28-286.

13. Franceschi, C., D. Monti, P. Sansoni \& A. Cossarizza. 1995. The immunology of exceptional individuals: the lesson of centenarians. Immunol. Today 16: 12-16.

14. RatTan, S.I.S. 1985. Beyond the present crisis in gerontology. BioEssays 2: 226228.

15. JAZWINSKI, S.M. 1996. Longevity, genes, and aging. Science 273: 54-59.

16. FInCH, C.E. \& R.E. TANZI. 1997. Genetics of aging. Science 278: 407-411.

17. Miller, R.A. 1999. Kleemeir award lecture: Are there genes for aging? J. Gerontol. Biol. Sci. 54A: B297-B307.

18. JaZwinski, S.M., S. Kim, C.-Y. Lai \& A. Benguria. 1998. Epigenetic stratification: the role of individual change in the biological aging process. Exp. Gerontol. 33: $571-580$.

19. JAZWINSKI, S.M. 1998. Genetics of longevity. Exp. Gerontol. 33: 773-783.

20. JAZWINSKI, S.M. 1999. Longevity, genes, and aging: a view provided by a genetic model system. Exp. Gerontol. 34: 1-6.

21. Guarente, L. 1997. Link between aging and the nucleolus. Gene. Dev. 11: 24492455.

22. Sinclair, D.A., K. Mills \& L. Guarente. 1997. Accelerated aging and nucleolar fragmentation in yeast $s g s 1$ mutants. Science 277: 1313-1316.

23. Morris, J.Z., H.A. Tissenbaum \& G. Ruvkun. 1996. A phosphatidylinositol-3-OH kinase family member regaulating longevity and diapause in Caenorhabditis elegans. Nature 382: 536-539.

24. Kimura, K.D., H.A. Tissenbaum, Y. Liu \& G. Ruvkun. 1997. daf-2, an insulin receptor-like gene that regulates longevity and diapause in Caenorhabditis elegans. Science 277: 942-946.

25. Lin, K., J.B. Dorman, A. Rodan \& C. KenYon. 1997. daf-16: an HNF-3/forkhead family member that can function to double the life-span of Caenorhabditis elegans. Science 278: 1319-1322.

26. OgG, S., S. Paradis, S. Gottlieb, et al. 1997. The fork head transcription factor DAF-16 transduces insulin-like metabolic and longevity signals in C. elegans. Nature 389: 994-999.

27. Lakowski, B. \& S. Hekimi. 1996. Determination of life-span in Caenorhabditis elegans by four clock genes. Science 272: 1010-1013.

28. YANG, Y. \& D.L. WILSON. 1999. Characterization of life-extending mutation in age-2, a new aging gene in Caenorhabditis elegans. J. Gerontol. Biol. Sci. 54A: B13-B142.

29. Lin, Y.-J., L. SERoude \& S. BenZer. 1998. Extended life-span and stress resistance in the Drosophila mutant methuselah. Science 282: 943-946.

30. Kuro-o, M., et al. 1997. Mutation of the mouse klotho gene leads to a syndrome resembling ageing. Nature 390: $45-51$.

31. Yu, C.-E., et al. 1996. Positional cloning of the Werner's syndrome gene. Science 272: 258-P262.

32. Gelman, R., A. Watson, R. Bronson \& E. Yunis. 1988. Murine chromosomal regions correlated with longevity. Genetics 118: 693-704.

33. Miller, R.A., C. ChrisP, A.U. JACKSON \& D. Burke. 1998. Marker loci associated with life span in genetically heterogeneous mice. J. Gerontol. Med. Sci. 53A: M257-M263.

34. De HaAn, G., R. Gelman, A. Watson, et al. 1998. A putative gene causes variability in lifespan among gentoypically identiacal mice. Nat. Genet. 19: 114-116.

35. Schächter, F., L. FAure-Delanef, F. Guénot, et al. 1994. Genetic associations with human longevity at the APOE and ACE loci. Nature Genet. 6: 29-32.

36. Jian-Gang, Z., M. Yong-XING, W. ChuAn-Fu, et al. 1998. Apolipoprotein E and longevity among Han Chinese population. Mech. Ageing Dev. 104: 159-167.

37. Martin, G.M. 1997. The Werner mutation: does it lead to a "public" or "private" mechanism of aging? Mol. Med. 3: 35-358.

38. NoDA, A., Y. Ning, S.F. Venable, et al. 1994. Cloning of senescent cell-derived inhibitors of DNA synthesis using an expression screen. Exp. Cell. Res. 211: 90-98.

39. Wong, H. \& K. Riabowol. 1996. Differential CDK-inhibitor gene expression in aging human diploid fibroblasts. Exp. Gerontol. 31: 311-325. 
40. Whitaker, N.J., T.M. Bryan, P. Bonnefin, et al. 1995. Involvement of RB-1, p53, p16 ${ }^{\mathrm{INK} 4}$ and telomerase in immortalisation of human cells. Oncogene 11: 971-976.

41. Stein, G.H., L.F. Drullinger, A. Soulard \& V. Dulic. 1999. Differential roles for cyclin-dependent kinase inhibitors p21 and p16 in the mechanisms of senescence and differentiation in human fibroblasts. Mol. Cell. Biol. 19: 2109-2117.

42. Alcorta, D.A., Y. Xiong, D. Phelps, et al. 1996. Involvement of the cyclin-dependent kinase inhibitor p16 (INK4a) in replicative senescence of normal human fibroblasts. Proc. Natl. Acad. Sci. USA 93: 13742-13747.

43. KАMB, A. et al. 1994. A cell cycle regulator potentially involved in genesis of many tumor types. Science 264: 436-440.

44. Jacobs, J.J.L., K. Kieboom, S. Marino, et al. 1999. The oncogene and polycomgroup gene bmi-1 regulates cell proliferation and senescence through ink $4 a$ locus. Nature 397: 164-168.

45. Derventzi, A., E.S. Gonos \& S.I.S. Rattan. 1996. Ageing and cancer: a struggle of tendencies. In Molecular Gerontology - Research Status and Stratgies. S.I.S. Rat$\tan \&$ O. Toussaint, Eds.: 15-23. Plenum Press. New York.

46. Derventzi, A., S.I.S. RatTAn \& E.S. Gonos. 1996. Molecular links between cellular mortality and immortality. Anticancer Res. 16: 2901-2910.

47. Gao, C.Y. \& P.S. ZelenKa. 1997. Cyclins, cyclin-dependent kinases and differentiaion. BioEssays 19: 307-315.

48. Dulic', V., L.F. Drullinger, E. LeEs, et al. 1993. Altered regulation of G1 cyclins in senescent human diploid fibroblasts: accumulation of inactive cyclin E-Cdk2 and cyclin D1-Cdk2 complexes. Proc. Natl. Acad. Sci. USA 90: 11034-11038.

49. Hengst, L., V. Dulic, J.M. Slingerland, et al. 1994. A cell cycle-regulated inhibitor of cyclin-dependent kinases. Proc. Natl. Acad. Sci. USA 91: 5291-5295.

50. REDDEL, R.R. 1998. A reassessment of the telomere hypothesis of senescence. BioEssays 20: $977-984$.

51. Faragher, R.G.A., C.J. Jones \& D. KiPling. 1998. Telomerase and cellular lifespan: ending the debate? Nat. Biotechnol. 16: 701-702.

52. Toussaint, O., et al. 1998. Reciprocal relationship between the resistance to stresses and cellular aging. Ann. N. Y. Acad Sci. 851: 450-465.

53. von Zglinicki, T., G. SARETZKi, W. DöcKe \& C. LotZe. 1995. Mild hyperoxia shortens telomeres and inhibits proliferation of fibroblasts: a model for senescence? Exp. Cell Res. 220: 186-193.

54. Sartezki, G., J. Feng, T. von Zaglinicki \& B. Villeponteau. 1998. Similar gene expression pattern in senescent and hyperoxic-treated fibroblasts. J. Gerontol. Biol. Sci. 53A: B438-B442.

55. Derventzi, A. \& S.I.S. Rattan. 1991. Homeostatic imbalance during cellular ageing: altered responsiveness. Mutat. Res. 256: 191-202.

56. RatTAn, S.I.S. \& A. DeRVEnTZI. 1991. Altered cellular responsiveness during ageing. BioEssays 13: 601-606.

57. Neafsey, P.J. 1990. Longevity hormesis: a review. Mech. Ageing Dev. 51: 1-31.

58. Pollycove, M. 1995. The issue of the decade: hormesis. Eur. J. Nucl. Med. 22: 399401.

59. Calabrese, E.J. 1997. Hormesis revisited: new insights concerning the biological effects of low-dose exposure to toxins. Environ. Law Rep. 27: 10526-10532.

60. Calabrese, E.J. \& L.A. Baldwin. 1999. Chemical hormesis: its historical foundations as a biological hypothesis. Toxicol. Pathol. 27: 195-216.

61. Khazaeli, A.A., M. Tatar, S.D. Pletcher \& J.W. Curtsinger. 1997. Heat-induced longevity extension in Drosophila. I. Heat treatment, mortality, and thermotolerance. J. Gerontol. Biol Sci. 52A: B48-B52.

62. Lithgow, G.J., T.M. White, S. Melov \& T.E. Johnson. 1995. Thermotolerance and extended life-span conferred by single-gene mutations and induced by thermal stress. Proc. Natl. Acad. Sci. USA 92: 7540-7544.

63. LithGOW, G.J. 1996. Invertebrate gerontology: the age mutations of Caenorhabditis elegans. BioEssays 18: 809-815.

64. Shama, S., C.-Y. Lai, J.M. Antoniazzi, et al. 1998. Heat stress-induced life span extension in yeast. Exp. Cell Res. 245: $379-388$. 
65. Le Bourg, E. \& N. MinoIs. 1999. A mild stress, hypergravity exposure, postpones behavioral aging in Drosophila melanogster. Exp. Gerontol. 34: 157-172.

66. Caratero, A., M. Courtade, L. Bonnet, et al. 1998. Effect of continuos gamma irradiation at a very low dose on the life span of mice. Gerontology 44: 272-276.

67. Busciglio, J., J.K. Andersen, H.M. Schipper, et al. 1998. Stress, aging, and neurodegenerative disorders. Ann. N.Y. Acad. Sci. 851: 429-443.

68. Wyngaarden, K.E.V. \& E.K.J. Pauwels. 1995. Hormesis: are low doses of ionizing radiation harmful or beneficial? Eur. J. Nucl. Med. 22: 481-486.

69. Johnson, T.E., G.J. Lithgow \& S. MuraKami. 1996. Interventions that increase the response to stress offer the potential for effective life prolongation and increased health. J. Gerontol. Biol. Sci. 51A: B392-B395.

70. RADÁK, Z., K. Asano, A. NAKAMURA, et al. 1998. The effect of high altitude and calorie restriction on reactive carbonyl derivatives and activity of glutamine synthetase in rat brain. Life Sci. 62: 1317-1322.

71. RADÁK, Z., A. NAKAMURA, H. NAKAMOTO, et al. 1998. A period of anaerobic exercise increases the accumulation of reactive carbonyl derivatives in the lungs of rats. Eur. J. Physiol. 435: 439-441.

72. MASORO, E.J. 1998. Hormesis and the antiaging action of dietary restriction. Exp. Gerontol. 33: 61-66.

73. Holliday, R. 1991. A re-examination of the effects of ionizing radiation on lifespan and transformation of human diploid fibroblasts. Mutat. Res. 256: 295-302.

74. ICARd, C., R. Beupain, C. Dialtoff \& A. Macieira-Coelho. 1979. Effect of low dose rate irradiation on the division potential of cells in vitro. VI. changes in DNA and in radiosensitivity during aging of human fibroblasts. Mech. Ageing Develop. 11: 269-278.

75. Yang, Z., S. Kodama, K. Suzuki \& M. Watanabe. 1998. Telomerase activity, telomere length, and chromosome aberrations in the extension of life span of human embryo cells induced by low-dose X-rays. J. Radiat. Res. 39: 35-51.

76. RATTAN, S.I.S. 1998. Repeated mild heat shock delays ageing in cultured human skin fibroblasts. Biochem. Mol. Biol. Int. 45: 753-759.

77. van Eden, W. \& D.B. Young, Eds. 1996. Stress Proteins in Medicine. Marcel Dekker. New York. 